\title{
Bilateral pulmonary artery banding for resuscitation in high-risk, single-ventricle neonates and infants: A single-center experience
}

\author{
Kristine J. Guleserian, MD, ${ }^{a}$ Gregory M. Barker, MD, ${ }^{\mathrm{b}}$ Mahesh S. Sharma, MD, ${ }^{\mathrm{a}}$ Joy Macaluso, RN, ${ }^{\mathrm{a}}$ \\ Rong Huang, PhD, ${ }^{b}$ Alan W. Nugent, MBBS, ${ }^{b}$ and Joseph M. Forbess, MD ${ }^{a}$
}

\begin{abstract}
Objectives: Bilateral pulmonary artery banding with or without ductal stenting has been performed as a resuscitative intervention for patients considered at too high risk for conventional single ventricle palliation. The purpose of the present study was to determine the outcomes using this strategy.
\end{abstract}

\begin{abstract}
Methods: We performed a retrospective review of 24 patients with single ventricle anatomy who were younger than 3 months who had undergone bilateral pulmonary artery banding and ductal stenting or maintenance of prostaglandin $E_{1}$ from January 2007 to October 2011 at our institution. The echocardiographic, angiographic, operative, and clinical data were reviewed. Follow-up data were available for $100 \%$ of the patients.
\end{abstract}

\begin{abstract}
Results: All 24 patients (13 male patients) underwent bilateral pulmonary artery banding at a median age of 8 days (range, 2-44 days). Their gestational age was 38 weeks (range, 27-41 weeks), and their weight was $3.01 \mathrm{~kg}$ (range, $1.5-4.4 \mathrm{~kg}$ ). The cardiac diagnoses included hypoplastic left heart syndrome/variant hypoplastic left heart syndrome in 18, unbalanced atrioventricular canal in 4 , and tricuspid atresia in 2 . In the hypoplastic left heart syndrome group, $9(50 \%)$ had an intact or a highly restrictive atrial septum requiring open $(\mathrm{n}=1)$ or transcatheter $(n=8)$ atrial septostomy with or without atrial stent placement $(n=4)$. Ductal stenting was performed in 14 patients, and 10 patients were continued with prostaglandin $\mathrm{E}_{1}$. Fifteen patients $(62.5 \%)$ survived to undergo a Norwood procedure $(n=7)$, comprehensive stage $2(n=1)$, or primary cardiac transplantation $(n=7)$. Of the 9 who died, support was withdrawn in 5 because of a contraindication to transplantation, 1 because of sepsis and/or multiorgan system failure, and 1 for whom palliative care was desired. Two died awaiting transplantation. All 7 patients who underwent a conventional Norwood operation survived to discharge, and 6 of the $7(85.7 \%)$ underwent bidirectional Glenn shunt placement. Of the 7 patients who underwent transplantation, $6(85.7 \%)$ were alive at a median follow-up of 33.6 months.
\end{abstract}

Conclusions: Bilateral pulmonary artery banding with or without ductal stenting is an effective method of resuscitation for high-risk neonates and infants with a single ventricle, allowing for reasonable survival to conventional first-stage palliation or primary transplantation. (J Thorac Cardiovasc Surg 2013;145:206-14)

Patients with hypoplastic left heart syndrome (HLHS), including variant HLHS and other complex congenital cardiac defects with functional single ventricle (SV) physiology and systemic outflow tract obstruction continue to be a challenge to even the most experienced congenital heart surgeon. Although operative mortality has steadily decreased from the time Norwood performed and reported his first successful procedure in 1981, ${ }^{1}$ "high-risk"

From the Divisions of Pediatric Cardiothoracic Surgery, ${ }^{a}$ and Pediatric Cardiology, University of Texas Southwestern Medical Center and Children's Medical Center, Dallas, Tex.

Disclosures: Authors have nothing to disclose with regard to commercial support.

Read at the 92nd Annual Meeting of The American Association for Thoracic Surgery, San Francisco, California, April 28-May 2, 2012.

Received for publication April 30, 2012; revisions received Aug 17, 2012; accepted for publication Sept 21, 2012.

Address for reprints: Kristine J. Guleserian, MD, Division of Pediatric Cardiothoracic Surgery, University of Texas Southwestern Medical Center and Children's Medical Center, 1935 Medical District Dr, Suite C-3211, Dallas, TX 75235-8835 (E-mail: Kristine.guleserian@utsouthwestern.edu).

$0022-5223 / \$ 36.00$

Copyright $(\odot) 2013$ by The American Association for Thoracic Surgery

http://dx.doi.org/10.1016/j.jtcvs.2012.09.063 neonates undergoing first-stage Norwood palliation still face mortality rates of $20 \%$ to $50 \%{ }^{2,3}$

Hybrid palliation consisting of bilateral pulmonary artery (PA) banding (bPAB) and ductal stenting (DS) or a "modified" hybrid approach consisting of bPAB and continuation of prostaglandin $\mathrm{E}_{1}\left(\mathrm{PGE}_{1}\right)$ are strategies that have been used for the initial palliation of HLHS until second-stage palliation is undertaken. ${ }^{4-6}$

Early success with the hybrid approach has prompted the increasing use of this strategy for "high-risk" patients with HLHS and other SV anatomy as a less-invasive initial procedure to optimize preoperative hemodynamics and, in turn, improve surgical outcomes. ${ }^{7-9}$ Ongoing controversy exists regarding what constitutes "high-risk" criteria, but these have included an intact atrial septum (IAS) or a restrictive atrial septum (RAS), profound metabolic acidosis or $\mathrm{pH}$ less than 7, renal insufficiency/failure, moderate or greater atrioventricular valve regurgitation (AVVR), a diminutive aorta, severe ventricular dysfunction, low birth weight, prematurity, preoperative cerebrovascular accident, and/or the presence of an extracardiac syndrome., ${ }^{2,3}$ Controversy 

Abbreviations and Acronyms
AVVR = atrioventricular valve regurgitation
$\mathrm{bPAB}=$ bilateral pulmonary artery banding
CS2 = comprehensive stage 2
DS = ductal stent/ductal stenting
$\mathrm{ECMO}=$ extracorporeal membrane oxygenation
HAA = hypoplastic aortic arch
HLHS = hypoplastic left heart syndrome
IAS = intact atrial septum
NIRS = near-infrared spectroscopy
$\mathrm{PA}=$ pulmonary artery
$\mathrm{PaO}_{2}=$ partial pressure of oxygen
PDA = patent ductus arteriosus
$\mathrm{PGE}_{1}=$ prostaglandin $\mathrm{E}_{1}$
POD = postoperative day
RAS = restrictive atrial septum
$\mathrm{SaO}_{2}=$ oxygen saturation
$\mathrm{SV}=$ single ventricle

continues regarding the optimal timing and appropriate choice for the second-stage procedure.

At Children's Medical Center (Dallas, Tex), we have performed $\mathrm{bPAB}$ and $\mathrm{DS}$ or continuation of $\mathrm{PGE}_{1}$ in our "high-risk" neonates and infants with HLHS or other SV physiology with systemic outflow tract obstruction for resuscitation and stabilization of these challenging patients as a bridge to conventional Norwood palliation or primary cardiac transplantation when absolute contraindications to Norwood palliation are present.

\section{METHODS \\ Study Design}

We performed a retrospective review of all patients with anatomic or functional SV anatomy who were younger than 3 months and who underwent $\mathrm{bPAB}$ and DS or maintenance of $\mathrm{PGE}_{1}$ from January 2007 to October 2011 at Children's Medical Center. All clinical, echocardiographic, angiographic, and operative data were reviewed. The heart rate, systolic, diastolic, and mean blood pressure, oxygen saturation $\left(\mathrm{SaO}_{2}\right)$, partial pressure of oxygen $\left(\mathrm{PaO}_{2}\right)$, head and flank near-infrared spectroscopy (NIRS), arteriovenous oxygen difference (using the NIRS data as a surrogate for mixed venous saturation), hemoglobin, lactate, net fluid balance, urine output, serum creatinine, and base deficit recorded immediately before $\mathrm{BPAB}$, 24 hours after bPAB, and 4 days after bPAB. Patients receiving extracorporeal membrane oxygenation (ECMO) support $(n=4 ; 2$ before bPAB and 2 after bPAB) were excluded from the analysis of the hemodynamic, laboratory, and fluid balance data. The risk factors for hospital death were assessed. Follow-up was complete for all 24 patients (100\%).

\section{Definitions}

Patients who died before hospital discharge (including those awaiting transplantation) or within 30 days of bPAB were designated as hospital deaths according to the Society of Thoracic Surgeons National Database criteria. Patients listed for cardiac transplantation who were inactivated (United Network for Organ Allocation status 7) and died within 6 months of listing were considered "wait list mortalities" and also designated as hospital deaths.
A restrictive atrial septum (RAS) was defined as a color flow jet width of $3 \mathrm{~mm}$ or less across the interatrial septum on the echocardiogram. ${ }^{10} \mathrm{Ven}$ tricular dysfunction and AVVR were graded as mild, moderate, or severe according to the echocardiographic data. Renal failure was defined as anuria or the need for dialysis. Renal insufficiency was defined as oliguria with an increasing creatinine.

\section{Management of IAS or RAS}

For neonates with an IAS or RAS diagnosed prenatally, rapid planned transfer from the delivery room to the cardiac catheterization laboratory for emergent radiofrequency perforation or transseptal puncture, balloon atrial septostomy, and atrial stent placement (premounted Genesis stent), in appropriate patients, was undertaken. For those with a postnatal diagnosis of IAS or RAS, similar procedures were performed immediately after the echocardiographic diagnosis.

\section{Operative Technique for bPAB}

$\mathrm{bPAB}$ procedures were performed in the operating room or cardiac catheterization laboratory (when DS performed simultaneously) with the patient under general anesthesia. After standard median sternotomy and minimal branch PA mobilization, 3.5-mm Gore-Tex grafts were sectioned and secured around the left and right branch PAs to achieve a 10- to $15-\mathrm{mm} \mathrm{Hg}$ increase in blood pressure, $10 \%$ to $15 \%$ decrease in oxygen $\mathrm{SaO}_{2}$, and 10 - to $15-\mathrm{mm} \mathrm{Hg}$ decrease in $\mathrm{PaO}_{2}$. The right $\mathrm{PA}$ band was positioned laterally to the ascending aorta. The bands were affixed to the adventitia of the respective branch PAs to prevent migration. Small hemoclips clips were applied for radiographic identification of the banding sites. Intracardiac lines, pacing wires, and an abdominal drain were placed. The sternum was closed, unless the patients had significant intraoperative dysrhythmias or anasarca.

\section{Catheterization Technique for DS Placement}

The DS procedures were performed in the cardiac catheterization laboratory with the patient under general anesthesia. After obtaining percutaneous femoral access, the patent ductus arteriosus (PDA) was crossed antegrade with a guidewire over which either a self-expanding or premounted stent was advanced and deployed to position the stent within the full length of the PDA. For patients who underwent simultaneous bPAB and DS placement, direct transpulmonary DS placement was performed using a $6 \mathrm{~F}$ sheath inserted through a 5-0 Prolene purse-string suture.

\section{Aortic Arch Reconstruction, DS Removal, and PA Debanding During Surgical Palliation and Transplantation}

At the Norwood procedure or comprehensive stage 2 (CS2) palliation, after beginning cardiopulmonary bypass, the DS was divided between the hemoclips. The proximal stent was removed from the main PA, and the distal main PA was either oversewn primarily or closed with a patch of autologous pericardium, if necessary. Using selective cerebral perfusion and after cardioplegic arrest, the distal stent was removed from the proximal descending aorta and the area s debrided to normal tissue to prevent aortic dissection. Standard neoaortic arch reconstruction was undertaken using a pulmonary homograft.

For patients undergoing primary transplantation, an end-to-end donor descending thoracic aortic to recipient descending thoracic aortic anastomosis was performed. A recipient brachiocephalic button or "island"-todonor transverse arch anastomosis using selective cerebral perfusion was performed, as previously described. ${ }^{11}$

The PA bands were removed, and all adventitial scar tissue was sharply excised. The branch PAs were assessed by both visual inspection and calibrated vascular dilators. When indicated, branch pulmonary arterioplasty was performed using pulmonary homograft, donor PA, or donor pericardium. 


\section{Statistical Analysis}

Continuous variables are presented as the mean \pm standard deviation or median and range. Dichotomous variables are presented as the count and percentages. The categorical data were compared using Fisher's exact test or the chi-square test, as appropriate. The Student $t$ test was used to screen the risk factors for hospital death. A mixed model was used to compare the baseline values to the post-bPAB values at 24 hours and 4 days postoperatively. Analysis was performed with SAS software (SAS Institute, Cary, NC).

The institutional review board at Children's Medical Center approved the present study, and the need for patient consent was waived.

\section{RESULTS}

A total of 24 consecutive patients (13 male patients, $54.2 \%$ ) underwent bPAB with maintenance of ductal patency by either DS $(n=14)$ or $\operatorname{PGE}_{1}$ infusion $(n=10)$ during the study period. Two patients who presented in extremis underwent ECMO cannulation and bPAB at the ECMO decannulation. The sternum was closed in all but 6 patients ( 2 after ECMO decannulation and bPAB, 2 with anasarca, and 2 with intraoperative dysrhythmias).

The patient demographics, including the "high-risk" criteria, are listed in Table 1. The predominant cardiac diagnosis in the study group was HLHS or variant HLHS, present in 18 patients $(75 \%)$. Of the remaining 6 patients, 4 had an unbalanced atrioventricular canal and 2 had tricuspid atresia, d-transposition of the great arteries, and systemic outflow tract obstruction. The anatomic and subtype classification are presented in Table 2.

An IAS or RAS was present in $50 \%$ of the HLHS/variant HLHS group (9/18). Open atrial septostomy was performed at ECMO cannulation in a patient with HLHS and IAS who presented in extremis at 12 hours of life after cardiac arrest at a remote hospital. The remaining 8 patients underwent emergent transcatheter balloon atrial septostomy by way of radiofrequency perforation or transseptal puncture, as appropriate. Atrial stents were placed in 4 neonates, 2 with IAS and 2 with RAS, whose atrial septum was markedly thickened.

DS was performed in patients who were not considered suitable Norwood candidates and/or for whom primary transplantation was considered (severe AVVR, severe ventricular dysfunction, renal failure, Scimitar syndrome, or prematurity with respiratory distress syndrome). DS was performed simultaneously with bPAB in 7 patients, after bPAB in 6 patients, and before $\mathrm{bPAB}$ in 1 neonate who presented with a late diagnosis of HLHS, including a restrictive PDA with suprasystemic PA pressures at nearly 2 weeks of age.

\section{Hemodyamic, Fluid Balance, and Laboratory Values After bPAB}

After bPAB, a decrease occurred in the heart rate at 24 hours that became statistically significant by postoperative day (POD) $4(P=.005$; Table 3$)$. Also, a significant increase was seen in the systolic, diastolic, and mean blood
TABLE 1. Patient demographics and "high-risk" criteria $(n=24)$

\begin{tabular}{|c|c|}
\hline Variable & Patients (n) \\
\hline \multicolumn{2}{|l|}{ Patient demographics } \\
\hline Gender (\% male $)$ & $13(54.2 \%)$ \\
\hline Gestational age (wk) & $38(27-41)$ \\
\hline Birth weight (kg) & $3.02(0.9-4.1)$ \\
\hline Age at bPAB (wk) & $8(2-44)$ \\
\hline Weight at bPAB $(\mathrm{kg})$ & $3.01(1.5-4.4)$ \\
\hline Prenatal diagnosis & $11(45.8 \%)$ \\
\hline Extracardiac syndrome (all) & $7(29.2 \%)$ \\
\hline Heterotaxy & 4 \\
\hline Other & 3 \\
\hline PDA stent & $14(58.3 \%)$ \\
\hline $\mathrm{PGE}_{1}$ infusion & $10(41.7 \%)$ \\
\hline \multicolumn{2}{|l|}{ High-risk criteria } \\
\hline Birth weight $<2.5 \mathrm{~kg}$ & $4(16.7 \%)$ \\
\hline Gestational age $\leq 36 \mathrm{wk}$ & $6(25 \%)$ \\
\hline Intact/restrictive atrial septum & $9(37.5 \%)$ \\
\hline HLHS/variant HLHS & $9 / 18(50 \%)$ \\
\hline \multicolumn{2}{|l|}{ Preoperative metabolic acidosis } \\
\hline $\mathrm{pH}<7.2$ & $7(29.2 \%)$ \\
\hline $\mathrm{pH}<7.0$ & $5(20.1 \%)$ \\
\hline Preoperative AV valve regurgitation* & $7(29.2 \%)$ \\
\hline Preoperative renal insufficiency/failure $\dagger$ & $6(25 \%)$ \\
\hline Preoperative severe ventricular dysfunction & $5(20.1 \%)$ \\
\hline Preoperative cardiac arrest & $3(12.5 \%)$ \\
\hline Preoperative CVA or seizures & $2(8.3 \%)$ \\
\hline Preoperative ECMO support & $2(8.3 \%)$ \\
\hline \multicolumn{2}{|c|}{$\begin{array}{l}\text { Data presented as median (range) or n }(\%) . b P A B, \text { Bilateral pulmonary artery banding; } \\
P D A \text {, patent ductus arteriosus; } P G E_{l} \text {, prostaglandin } \mathrm{E}_{1} ; H L H S \text {, hypoplastic left heart } \\
\text { syndrome; } A V \text {, atrioventricular; } C V A \text {, cerebrovascular accident; } E C M O \text {, extracorpo- } \\
\text { real membrane oxygenation. } * \text { Preoperative AV regurgitation graded at least moderate } \\
\text { from echocardiographic findings. } \dagger \text { Renal insufficiency defined as oliguria with } \\
\text { increasing creatinine; renal failure defined as anuria and/or need for hemodialysis. }\end{array}$} \\
\hline
\end{tabular}

pressure at 24 hours that persisted at 4 days postoperatively $(P<.001)$.

As would be expected, both $\mathrm{SaO}_{2}$ and $\mathrm{PaO}_{2}$ were lower at 24 hours and 4 days after bPAB. Head NIRS was significantly greater at 24 hours $(P<.01)$ but not different from the pre-bPAB values at POD 4. No significant difference was found in the flank NIRS at either point. Using head NIRS as a surrogate for mixed venous saturation, a significant decrease was seen in the arteriovenous oxygen difference at both points $(P<.001)$. This difference was also observed when using flank NIRS as a surrogate, implicating a decreased $\mathrm{SaO}_{2}$ as predominantly responsible.

Although no difference was seen in the net fluid balance within the first 24 hours after bPAB, by POD 4, the difference was significant $(P<.0001)$. Similarly, although no difference was observed at 24 hours, a trend was seen toward an increased urine output noted by POD $4(P=.078)$.

The serum creatinine and lactate levels were not different at 24 hours; however, by POD 4, they had decreased significantly $(P<.001, P=.048)$. Similarly, the base excess was unchanged at 24 hours yet had significantly improved by POD $4(P=.016)$. An increase occurred in serum 
TABLE 2. Anatomic and subtype classification $(n=24)$

\begin{tabular}{|c|c|}
\hline Classification & Patients (n) \\
\hline HLHS & 14 \\
\hline MS/AS & 9 \\
\hline MS/AA & 3 \\
\hline MA/AA & 2 \\
\hline Variant HLHS & 4 \\
\hline MA/AS/VSD with type B IAA & 1 \\
\hline $\begin{array}{l}\text { Heterotaxy with mesocardia and primitive SV, } \\
\text { unobstructed TAPVC, RAA with vascular ring, } \\
\text { interrupted IVC }\end{array}$ & 1 \\
\hline $\begin{array}{l}\text { Dextrocardia with HLV, LVOT hypoplasia, and } \\
\text { straddling TV }\end{array}$ & 1 \\
\hline DORV/MA with AS & 1 \\
\hline Unbalanced AVC & 4 \\
\hline RV-dominant RAA, vascular ring, bilateral SVC & 1 \\
\hline RV-dominant CoA, unobstructed TAPVC & 1 \\
\hline $\begin{array}{l}\text { RV-dominant Ao atresia, HAA, LCA from right PA, } \\
\text { PAPVC/Scimitar syndrome }\end{array}$ & 1 \\
\hline LV-dominant CoA, HAA & 1 \\
\hline $\begin{array}{l}\text { Tricuspid atresia with d-TGA and LV outflow } \\
\text { tract obstruction }\end{array}$ & 2 \\
\hline \multicolumn{2}{|c|}{$\begin{array}{l}H L H S \text {, Hypoplastic left heart syndrome; } M S \text {, mitral stenosis; } A S \text {, aortic stenosis; } \\
A A \text {, aortic atresia; } M A \text {, mitral atresia; } V S D \text {, ventricular septal defect; } I A A \text {, interrupted } \\
\text { aortic arch; } S V \text {, single ventricle; } T A P V C \text {, total anomalous pulmonary venous connec- } \\
\text { tion; } R A A \text {, right aortic arch; } I V C \text {, inferior vena cava; } H L V \text {, hypoplastic left ventricle; } \\
L V O T \text {, left ventricular outflow tract; } T V \text {, tricuspid valve; } D O R V \text {, double outlet right } \\
\text { ventricle; } A V C \text {, atrioventricular canal; } R V \text {, right ventricle; } S V C \text {, superior vena cava; } \\
\text { Ao, aorta; } L C A \text {, left coronary artery; } P A \text {, pulmonary artery; } P A P V C \text {, partial anoma- } \\
\text { lous pulmonary venous connection; } C O A \text {, coarctation; } H A A \text {, hypoplastic aortic } \\
\text { arch; } d-T G A \text {, d-transposition of the great arteries; } L V \text {, left ventricular. }\end{array}$} \\
\hline
\end{tabular}

hemoglobin at 24 hours $(P=.043)$, likely reflective of blood transfusions given. The serum $\mathrm{pH}$ was not different at any point.

\section{Survival to Surgical Palliation or Primary Transplantation}

Of the 24 patients, $15(62.5 \%)$ survived to conventional Norwood ( $\mathrm{n}=7$; Blalock-Taussig shunt in 5, Sano shunt in 2$)$, CS2 $(n=1)$, or primary transplantation $(n=7$; Figure 1).

The median time to the Norwood procedure was 7 days (range, 4-78 days). One Norwood procedure performed at 78 days was in an infant with trisomy 21 and an unbalanced atrioventricular canal with coarctation/transverse arch hypoplasia for whom a 2-ventricle repair was planned but not performed given the complex atrioventricular valve anatomy.

One infant, who was readmitted from home, underwent CS2 palliation 118 days after bPAB/PDA stent placement.

Nine patients with contraindications to Norwood (severe AVVR with or without severe ventricular dysfunction) were listed for primary transplantation. Seven patients $(77.7 \%)$ underwent successful transplantation at a median of 89 days (range, 21-201 days) after bPAB.
TABLE 3. Hemodynamic, fluid balance, and laboratory variables*

\begin{tabular}{|c|c|c|c|}
\hline Variable & $\begin{array}{l}\text { Before } \\
\text { bPAB }\end{array}$ & $\begin{array}{c}\text { 24-h After } \\
\text { bPAB }\end{array}$ & $\begin{array}{c}4 \text { d After } \\
\text { bPAB }\end{array}$ \\
\hline HR (beats/min) & $153 \pm 14$ & $148 \pm 14$ & $143 \pm 13 \dagger$ \\
\hline $\mathrm{SBP}(\mathrm{mm} \mathrm{Hg})$ & $66 \pm 11$ & $72 \pm 9 \ddagger$ & $78 \pm 12 \S$ \\
\hline DBP (mm Hg) & $35 \pm 6$ & $41 \pm 5 \S$ & $40 \pm 5 \dagger$ \\
\hline MAP (mm Hg) & $46 \pm 6$ & $53 \pm 5 \S$ & $54 \pm 7 \S$ \\
\hline $\mathrm{SaO}_{2}(\%)$ & $92 \pm 5$ & $82 \pm 4 \S$ & $83 \pm 4 \S$ \\
\hline $\mathrm{PaO}_{2}(\mathrm{~mm} \mathrm{Hg})$ & $57 \pm 12$ & $43 \pm 4 \S$ & $44 \pm 5 \S$ \\
\hline NIRS head (\%) & $56 \pm 10$ & $63 \pm 9 \ddagger$ & $59 \pm 10$ \\
\hline NIRS flank (\%) & $60 \pm 12$ & $63 \pm 12$ & $60 \pm 13$ \\
\hline \multicolumn{4}{|l|}{$\begin{array}{l}\text { Arteriovenous oxygen } \\
\text { difference }(\%)\end{array}$} \\
\hline Head NIRS & $36 \pm 10$ & $19 \pm 9 \S$ & $24 \pm 12 \S$ \\
\hline Flank NIRS & $31 \pm 13$ & $19 \pm 12 \S$ & $23 \pm 14 \dagger$ \\
\hline Net intake/output balance $(\mathrm{mL})$ & $533 \pm 622$ & $458 \pm 572$ & $170 \pm 676$ \\
\hline Urine output $(\mathrm{mL} / \mathrm{kg} / \mathrm{h})$ & $3.7 \pm 1.7$ & $4.3 \pm 1.8$ & $4.7 \pm 2.4$ \\
\hline Creatinine $(\mathrm{mg} / \mathrm{dL})$ & $1.1 \pm 0.7$ & $0.9 \pm 0.7$ & $0.7 \pm 0.4 \S$ \\
\hline $\mathrm{pH}$ & $7.36 \pm 0.06$ & $7.36 \pm 0.06$ & $7.38 \pm 0.08$ \\
\hline Lactate (mg/dL) & $2.3 \pm 1.6$ & $2.1 \pm 2.2$ & $1.4 \pm 0.3 \dagger$ \\
\hline Base excess $(\mathrm{mEq} / \mathrm{L})$ & $0.7 \pm 4.6$ & $0.1 \pm 3.6$ & $3.9 \pm 4.4 \dagger$ \\
\hline Hemoglobin $(\mathrm{g} / \mathrm{dL})$ & $14.5 \pm 1.7$ & $15.5 \pm 1.8 \dagger$ & $14.7 \pm 1.5$ \\
\hline
\end{tabular}

$b P A B$, Bilateral pulmonary artery banding; $H R$, heart rate; $S B P$, systolic blood pressure; $D B P$, diastolic blood pressure; $M A P$, mean arterial pressure; $\mathrm{SaO}_{2}$, oxygen saturation; $\mathrm{PaO}_{2}$, partial pressure of oxygen; NIRS, near-infrared spectroscopy; $E C M O$, extracorporeal membrane oxygenation. *Patients receiving ECMO support (n $=4,2$ before and 2 after $\mathrm{bPAB}$ ) were excluded from analysis. $\dagger P<.01$ $\ddagger P<.05 . \S P<.001$.

\section{Hospital Deaths}

There were 9 hospital deaths $(37.5 \%)$. Of these 9 patients, 3 experienced cardiac arrest within hours of $\mathrm{bPAB}, 2$ of whom underwent emergent ECMO cannulation without meaningful cardiac recovery. Of the 3, 2 (including a former 33-week, 2.3-kg neonate) had a diminutive ascending aorta less than $1.5 \mathrm{~mm}$ and decompensated from coronary ischemia, presumed related to coronary distortion by the DS. The third patient (former 33-week, $1.8-\mathrm{kg}$ patient with respiratory distress syndrome) experienced

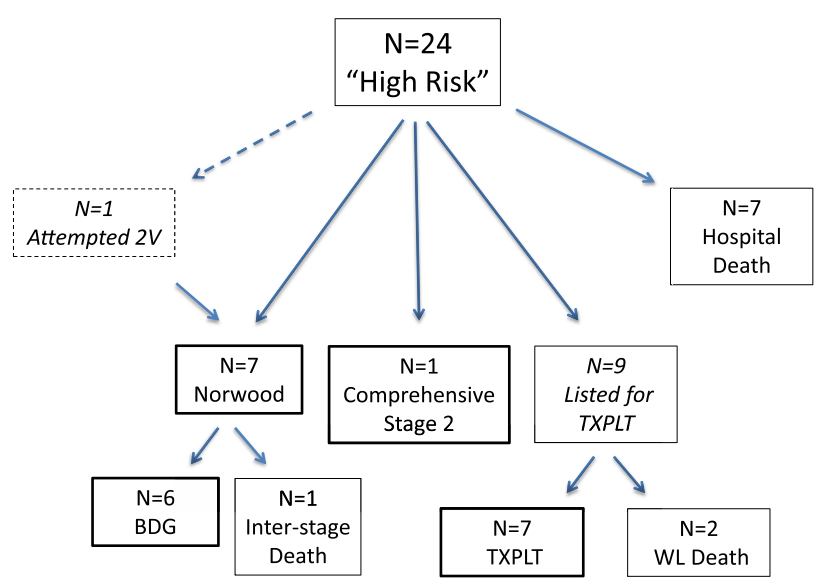

FIGURE 1. Outcomes after bilateral pulmonary artery banding in highrisk single ventricle patients. TXPLT, Transplant or transplantation; $B D G$, bidirectional Glenn shunt; $W L$, wait list. 
cardiovascular collapse secondary to profound respiratory acidosis. Support was withdrawn in 3 neonates with absolute contraindications to transplantation (chronic renal failure in 1, Scimitar syndrome or a hypoplastic right lung in 1, and uncontrolled sepsis in 1). One neonate discharged with palliative care per the family's request died at home several days later. Finally, support was withdrawn in 2 infants awaiting transplantation that was inactivated after they developed contraindications to transplantation (recurrent sepsis with renal failure in 1 and chronic lung disease in 1).

\section{Risk Factors for Death}

Gestational age, the presence of IAS or RAS, extracardiac syndrome (including heterotaxy), age at bPAB, age at the Norwood operation, CS2, or transplantation, preoperative profound metabolic acidosis, moderate or greater AVVR, poor ventricular function, renal insufficiency or renal failure, cardiac arrest, neurologic deficit, ECMO support, or strategy to maintain ductal patency ( $\mathrm{PGE}_{1}$ vs $\mathrm{DS}$ ) were not associated with any significant increased risk of hospital death. Although the birth weight had a borderline association with hospital death $(P=.055)$, no patient whose birth weight was less than $2.5 \mathrm{~kg}(\mathrm{n}=4)$ survived.

\section{Follow-up}

The median follow-up period for those who survived bPAB and DS or $\mathrm{PGE}_{1}$ was 1.58 years (range, 0.34-4.36 years), and the follow-up data were complete in all.

Of the 7 patients surviving Norwood palliation, 6 $(85.7 \%)$ subsequently underwent bidirectional cavopulmonary (Glenn) shunt, 2 of whom $(33.3 \%)$ required subsequent left PA angioplasty or stent placement.

Of the 7 patients undergoing primary transplantation, 6 $(85.7 \%)$ were alive at a median follow-up of 33.6 months. Of these 7 patients, $4(57.1 \%)$ underwent pulmonary arterioplasty at transplantation ( 3 bilateral and 1 right PA) but underwent no additional PA interventions. One patient transplanted 3 years previously underwent balloon angioplasty at 1 month and 1 year after transplantation with a good angiographic result.

\section{Late Deaths}

The patient characteristics and outcomes for the entire cohort are listed in Table 4. There were 4 late deaths (4/ $15,26.6 \%)$. One death occurred 3 months after primary transplantation in 1 patient who presented in extremis with HLHS and IAS requiring emergent ECMO support. She was found to have left PA stenosis (stent placed) and right-sided pulmonary vein stenosis at cardiac catheterization, immediately after which she developed pulmonary hemorrhage and worsening respiratory failure, from which she died.

One patient with HLHS and RAS developed respiratory failure 1 month after CS2, secondary to influenza B and the development of branch PA thrombosis. Despite anticoagulation and aggressive catheter-based and surgical pulmonary thrombectomy, she died.

One death occurred secondary to RSV bronchiolitis 2.5 years after a Glenn shunt procedure in a patient with trisomy 21.

Finally, 1 interstage death occurred at home in an infant with HLHS and mosaic Turner syndrome 2 months after a Norwood procedure and is presumed secondary to aspiration.

\section{DISCUSSION}

HLHS was a uniformly fatal condition until the Norwood procedure was first developed in the 1970s and cardiac transplantation was introduced in the 1980s. Additional modification of first-stage palliation occurring in the 1990s and into the new millennium has allowed for improved surgical survival. ${ }^{1,4,12}$ In the present era, the operative mortality for the Norwood procedure, now also applied to a variety of complex congenital cardiac defects with a functional SV and associated systemic outflow tract obstruction, has been reported to be as low as $10 \%$ to $20 \%$ in specialized centers. ${ }^{13,14}$ Greater operative mortality has been reported for patients with an IAS or highly RAS, preoperative shock with profound metabolic acidosis or $\mathrm{pH}$ less than 7 , renal failure, a diminutive or small ascending aorta, prematurity, low birth weight, ventricular dysfunction, significant AVVR, and/or the presence of extracardiac and chromosomal disorders, not only for patients undergoing reconstructive surgical palliation, but also for those awaiting cardiac transplantation., ${ }^{7,15-18}$

A reduction of pulmonary blood flow by PA banding was first reported by Gibbs and colleagues ${ }^{19}$ as an alternative to a Norwood procedure in newborns. This strategy has since been expanded to other forms of SV and even 2-ventricle anatomy in an attempt to optimize severe Qp/Qs imbalance that might otherwise lead to multiorgan system dysfunction from which recovery might not be possible. ${ }^{20-22}$

The presence of multiorgan system dysfunction before planned surgical intervention can lead to additional organ impairment from cardiopulmonary bypass and a period of circulatory arrest. Pharmacologic manipulation and ventilatory maneuvers might be inadequate in the common scenario of hypotension and markedly elevated systemic vascular resistance. Mechanical limitation of pulmonary blood flow, in concert with augmentation of systemic perfusion, must be achieved.

In the present series, bPAB was performed to limit mechanically systolic pulmonary flow and diastolic runoff into the pulmonary circulation when attempts at pharmacologic manipulation and ventilatory strategies failed to restore effective systemic perfusion. Shortly after bPAB, significant improvement was seen in systemic perfusion, as evidenced by expected increases in the systolic, diastolic, and mean 
TABLE 4. Patient characteristics and outcomes

\begin{tabular}{|c|c|c|c|c|c|c|c|c|c|c|}
\hline $\begin{array}{l}\text { Pt. } \\
\text { no. }\end{array}$ & Diagnosis & $\begin{array}{c}\text { Birth } \\
\text { weight } \\
\text { (kg) }\end{array}$ & $\begin{array}{c}\text { Gestational } \\
\text { age (wk) }\end{array}$ & $\begin{array}{c}\text { Fetal } \\
\text { diagnosis }\end{array}$ & IAS/RAS & $\begin{array}{c}\text { Moderate } \\
\text { or greater } \\
\text { AVVR }\end{array}$ & RI/RF & $\begin{array}{c}\text { Poor } \\
\text { function }\end{array}$ & $\begin{array}{c}\text { Extracardiac } \\
\text { syndrome }\end{array}$ & Outcome \\
\hline 1 & HLHS & 3.8 & 39 & No & IAS & No & Yes & Yes & No & Transplantation, late death \\
\hline 2 & HLHS & 3.7 & 39 & No & - & Yes & Yes & No & No & Hospital death \\
\hline 3 & HLHS & 2.9 & 39 & No & RAS & No & No & No & No & $\mathrm{CS} 2$, late death \\
\hline 4 & HLHS & 3.0 & 37 & Yes & RAS & Yes & No & No & No & Hospital death \\
\hline 5 & Unbalanced AVC & 3.1 & 40 & Yes & - & No & No & No & Heterotaxy & Transplantation \\
\hline 6 & HLHS & 1.8 & 33 & Yes & - & No & No & No & No & Hospital death \\
\hline 7 & HLHS variant & 3.4 & 36 & No & - & No & No & Yes & No & Transplantation \\
\hline 8 & HLHS & 3.9 & 38 & No & IAS & No & Yes & No & No & Transplantation \\
\hline 9 & Unbalanced AVC & 3.0 & 37 & Yes & - & Yes & No & No & Trisomy 21 & Norwood/BTS, late death \\
\hline 10 & HLHS & 2.3 & 33 & No & - & Yes & No & Yes & No & Hospital death (WL mortality \\
\hline 11 & HLHS & 3.4 & 37 & Yes & - & No & Yes & No & No & Hospital death (WL mortality \\
\hline 12 & TA, d-TGA, LVOTO & 1.6 & 35 & No & - & No & No & No & Heterotaxy & Hospital death \\
\hline 13 & HLHS variant & 3.3 & 38 & No & - & Yes & No & Yes & Heterotaxy & Transplantation \\
\hline 14 & Unbalanced AVC & 3.3 & 40 & No & - & No & No & No & Heterotaxy & Hospital death \\
\hline 15 & HLHS variant & 3.2 & 38 & No & - & Yes & No & No & No & Transplantation \\
\hline 16 & HLHS & 3.2 & 39 & Yes & RAS & No & No & No & No & Norwood/Sano \\
\hline 17 & HLHS variant & 3.2 & 39 & No & RAS & No & Yes & No & Other & $\begin{array}{l}\text { Hospital death (palliative } \\
\text { care) }\end{array}$ \\
\hline 18 & HLHS & 3.4 & 40 & Yes & RAS & No & No & No & No & Norwood/Sano \\
\hline 19 & TA, d-TGA, LVOTO & 0.9 & 27 & No & - & No & No & No & No & Hospital death \\
\hline 20 & HLHS & 3.4 & 40 & Yes & IAS & No & No & No & No & Norwood/BTS \\
\hline 21 & HLHS with PAPVC & 2.9 & 36 & Yes & - & No & Yes & No & No & Norwood/BTS \\
\hline 22 & HLHS & 4.1 & 38 & No & RAS & No & No & No & No & Norwood/BTS \\
\hline 23 & Unbalanced AVC & 3.7 & 39 & Yes & - & Yes & No & No & No & Transplantation \\
\hline 24 & HLHS & 3.0 & 41 & No & - & No & No & Yes & Turner's (mosaic) & Norwood/BTS, late death \\
\hline
\end{tabular}

Pt. no., Patient number; $A V V R$, atrioventricular valve regurgitation; $I A S$, intact atrial septum; $R A S$, restrictive atrial septum; $R I$, renal insufficiency; $R F$, renal failure; $H L H S$, hypoplastic left heart syndrome; $A V C$, atrioventricular canal; $C S 2$, comprehensive stage 2; BTS, Blalock-Taussig shunt; $W L$, wait list; $T A$, tricuspid atresia; $d$-TGA, d-transposition of the great arteries; LVOTO, left ventricular outflow tract obstruction; PAPVC, partial anomalous pulmonary venous connection.

arterial blood pressure, a decrease in $\mathrm{SaO}_{2}$ and $\mathrm{PaO}_{2}$ (with resultant improvement in the arteriovenous oxygen difference, net fluid balance, and urine output), and improvement in serum creatinine, lactate, and base excess over time. This beneficial effect provided the necessary conditions for the recovery of organ dysfunction, allowing for CS2 in 1 patient, a conventional Norwood operation in 7 patients (our preferred approach), and primary transplantation in 7 patients in whom Norwood palliation was contraindicated.

Caldarone and colleagues ${ }^{23}$ found similar 1-year survival in patients who underwent bPAB and PDA stenting as part of their newly established hybrid program as a Norwood alternative, pretransplantation stabilization procedure, or salvage procedure and those who underwent the Norwood operation in their well established program (survival, 68\% vs $71.4 \%, P=.56$ ). In contrast to our study, only a small number of "high-risk" or salvage patients were included. ${ }^{23}$

Although in many published series, the hybrid approach is targeted for usual-risk patients as a Norwood alternative or has been used for a limited number of "high-risk" patients, there appears to be recent heightened interest in its application as a resuscitation strategy for this growing and increasingly difficult subgroup.
Lim and colleagues ${ }^{7}$ reported their risk-stratified approach to first-stage palliation, showing markedly improved operative survival in 5 infants with HLHS and "high-risk" features (severe tricuspid regurgitation, severe right ventricular dysfunction, IAS or RAS, an ascending aortic of $2 \mathrm{~mm}$ or less, late presentation, weight less than $2 \mathrm{~kg}$, or significant extracardiac issues) undergoing hybrid palliation compared with 7 infants with similar "high-risk" features and 10 infants without "high-risk" features undergoing the Norwood operation or Sano procedure (100\% vs $29 \%$ vs $90 \%$, respectively). ${ }^{7}$

Sasaki and colleagues ${ }^{8}$ reported their experience with bPAB and $\mathrm{PGE}_{1}$ in 12 "high-risk" patients with HLHS or similar anomalies. Because of their concerns for high interstage morbidity with ductal constriction, inadequate growth of the ascending aorta, and the development of branch PA stenosis in 3 patients, they suggested that early conversion to the Norwood operation might be beneficial. ${ }^{8}$

In their recent series of 21 "high-risk " neonates, Venugopal and colleagues ${ }^{9}$ reported findings somewhat similar to those from our series. Of their 14 patients who survived bPAB and DS, however, 9 subsequently underwent CS2 ( 2 died postoperatively), and 3 were able to undergo 
biventricular repair. ${ }^{9}$ In their series, no patient was bridged to conventional Norwood or primary transplantation. ${ }^{9}$

We attempted to identify "high-risk" SV neonates and intervene in a timely fashion to optimize their resuscitation with the intent to perform early conventional Norwood palliation. In those patients with significant AVVR and/or persistent severe ventricular dysfunction, we used bPAB and maintenance of ductal patency as the initial resuscitation and later stabilization as the "bridge" to primary cardiac transplantation. Not unexpectedly, the median interval to primary transplantation was greater than 10 -fold longer than the median interval to the Norwood operation. An increased frequency of branch PA intervention was associated with a longer banding time. This is a problem with which we are particularly attuned to in the treatment of our current and future patients.

Birth weight less than $2.5 \mathrm{~kg}$ was associated with $100 \%$ mortality in our cohort. Similarly, in other centers, birth weight has continued to be a significant risk factor for hospital death; thus, strategies to improve survival for this "highest-risk" group warrant additional investigation. DS in the presence of a diminutive aorta was associated with coronary ischemia and is not recommended.

Although not highlighted in the present analysis, operative mortality at the Norwood palliation or primary transplantation for those patients successfully resuscitated with bPAB/DS or PGE $_{1}$ was comparable to that of our "usual" risk patients when comparing similar periods.

Owing to the relatively small number of patients in the present series and heterogeneity at the initial presentation, the identification of risk factors for morbidity and mortality was a challenge. A larger prospective investigation of such "high-risk" neonates would be instrumental to further identify modifiable — and nonmodifiable — risk factors to optimize patient selection. Improving the number of fetal diagnoses, for example, might potentially reduce the incidence of immediate postnatal cardiovascular collapse and allow for earlier-even fetal-intervention, particularly for patients with IAS or RAS. ${ }^{24}$ Measures to delay preterm delivery in appropriate cases to maximize in utero growth and development might be warranted.

Longer term follow-up with larger patient numbers is also necessary to determine whether more optimal outcomes might be obtained with primary transplantation, remembering the scarcity of donor hearts, particularly in the neonatal/infant population. ${ }^{25}$ Finally, the role of hybrid stage 1 palliation in the management of usual-risk patients with HLHS and its variants remains to be defined, especially because the results of conventional surgical management continue to improve.

\section{Study Limitations}

The limitations of the present study included those inherent to a retrospective nonrandomized analysis at a single institution with respect to the relatively small number of patients, heterogeneous patient population, and inherent institutional bias with respect to critical care, interventional, and operative management strategies.

\section{CONCLUSIONS}

Bilateral PA banding and maintenance of ductal patency with either DS or $\mathrm{PGE}_{1}$ is an effective method of resuscitation for "high-risk" SV neonates and infants. This strategy allows for reasonable survival to either conventional Norwood palliation or primary transplantation, when appropriate. DS in the presence of a diminutive ascending aorta could compromise coronary perfusion and should be avoided. Branch PA intervention is more frequent in patients requiring banding for longer periods. Early conventional Norwood palliation is therefore optimal when possible, and a thorough assessment of branch PAs must be undertaken at transplantation. A birth weight less than $2.5 \mathrm{~kg}$ continues to be a significant risk factor for in-hospital death.

\section{References}

1. Norwood WI, Kirklin JK, Sanders SP. Hypoplastic left heart syndrome: experience with palliative surgery. Am J Cardiol. 1980;45:87-91.

2. Gaynor JW, Mahle WT, Cohen MI, Ittenback RF, DeCampli WM, Steven JM, et al. Risk factors for mortality after the Norwood procedure. Eur J Cardiothorac Surg. 2002;22:82-9.

3. Stasik CN, Goldberg CS, Bove EL, Devaney EJ, Ohye RG. Current outcomes and risk factors for the Norwood procedure. J Thorac Cardiovasc Surg. 2006;131: 412-7.

4. Galantowicz M, Cheatham JP. Lessons learned from the development of a new hybrid strategy for the management of hypoplastic left heart syndrome. Pediatr Cardiol. 2005;26:190-9.

5. Akintüerk H, Michel-Behnke I, Valeske K, Mueller M, Thul J, Bauer J, et al. Stenting of the arterial duct and banding of the pulmonary arteries: basis for combined Norwood stage I and II repair in hypoplastic left heart. Circulation. 2002; 105:1099-103.

6. Sakurai T, Kado H, Nakano T, Hinokiyama K, Shiose A, Kajimoto M, et al. Early results of bilateral pulmonary artery banding for hypoplastic left heart syndrome. Eur J Cardiothorac Surg. 2009;36:973-9.

7. Lim DS, Peeler BB, Matherne GP, Kron IL, Gutgesell HP. Risk-stratified approach to hybrid transcatheter-surgical palliation of hypoplastic left heart syndrome. Pediatr Cardiol. 2006;27:91-5.

8. Sasaki T, Takahashi Y, Ando M, Wada N, Kawase Y, Seki H. Bilateral pulmonary artery banding for hypoplastic left heart syndrome and related anomalies. Gen Thorac Cardiovasc Surg. 2008;56:158-62.

9. Venugopal PS, Luna KP, Anderson DR, Austin CB, Rosenthal E, Krasemann T, et al. Hybrid procedure as an alternative to surgical palliation of high-risk infants with hypoplastic left heart syndrome and its variants. J Thorac Cardiovasc Surg. 2010;138:1211-5.

10. Dick M, Fyler D, Nadas AS. Tricuspid atresia: clinical course in 101 patients. Am J Cardiol. 1975;36:327-37.

11. Sebastian VA, Guleserian KJ, Leonard SR, Forbess JM. Heart transplantation techniques after hybrid single-ventricle palliation. J Card Surg. 2010;25: 596-600.

12. Sano S, Ishino K, Kawada M, Arai S, Kasahara S, Asai Masuda Z, et al. Right ventricle-pulmonary artery shunt in first-stage palliation of hypoplastic left heart syndrome. J Thorac Cardiovsc Surg. 2003;126:504-9.

13. Tweddell JS, Hoffman GM, Mussatto KA, Fedderly RT, Berger S, Jaquiss RD, et al. Improved survival of patients undergoing palliation of hypoplastic left heart syndrome: lessons learned from 115 consecutive patients. Circulation. 2002; 106(12 Suppl 1):182-9.

14. Karamichalis JM, del Nido PJ, Thiagarajan RR, Jenkins KJ, Liu H, Gauvreau K, et al. Early postoperative severity of illness predicts outcomes after the stage I Norwood procedure. Ann Thorac Surg. 2011;92:660-5. 
15. Hehir DA, Dominguez TE, Ballweg JA, Ravishankar C, Marino BS, Bird GL, et al. Risk factors for inter-stage death after stage 1 reconstruction of hypoplastic left heart syndrome and variants. J Thorac Cardiovasc Surg. 2008;136:94-9.

16. Curzon CL, Milford-Beland S, Li JS, O'Brien SM, Jacobs JP, Jacobs ML, et al. Cardiac surgery in infants with low birth weight is associated with increased mortality: analysis of the Society of Thoracic Surgeons Congenital Database. J Thorac Cardiovasc Surg. 2008;135:546-51.

17. Alsoufi B, Manlhiot C, Al-Ahmadi M, Al-Halees Z, McCrindle BW, Mousa AY, et al. Older children at the time of the Norwood operation have ongoing mortality vulnerability that continues after cavopulmonary connection. $J$ Thorac Cardiovasc Surg. 2011;142:142-7.

18. Canter CE, Moorhead S, Huddleston CB, Spray TL. Restrictive atrial septal communication as a determinant of outcome of cardiac transplantation for hypoplastic left heart syndrome. Circulation. 1993;88:II456-60.

19. Gibbs JL, Wren C, Watterson KG, Hunter S, Hamilton JR. Stenting of the arterial duct combined with banding of the pulmonary arteries and atrial septectomy or septostomy: a new approach to palliation for the hypoplastic left heart syndrome. Br Heart J. 1993;69:551-5.

20. Bacha EA, Daves S, Hardin J, Abdulla RI, Anderson J, Kahana M, et al. Singleventricle palliation for high-risk neonates: the emergence of an alternative hybrid stage I strategy. J Thorac Cardiovasc Surg. 2006;131:163-71.

21. Pizarro C, Derby CD, Baffa JM, Murdison KA, Radtke WA. Improving the outcome of high-risk neonates with hypoplastic left heart syndrome: hybrid procedure or conventional surgical palliation? Eur J Cardiothorac Surg. 2008;33:613-8.

22. Kawahira Y, Nishigaki K, Maehata Y. Bilateral pulmonary artery banding for extremely low birth weight infants with coarctation or interruption of the aorta weighing less than $1.0 \mathrm{~kg}$. J Thorac Cardiovasc Surg. 2010;139:1339-40.

23. Caldarone CA, Benson L, Holtby H, Li J, Redington AN, Van Arsdell GS. Initial experience with hybrid palliation for neonates with single-ventricle physiology. Ann Thorac Surg. 2007;84:1294-300.

24. Tworetzky W, McElhinney DB, Reddy VM, Brook MM, Hanley FL, Silverman NH. Improved surgical outcome after fetal diagnosis of hypoplastic left heart syndrome. Circulation. 2001;103:1269-73.

25. Chrisant MR, Naftel DC, Drummond-Webb J, Chinnock R, Canter CE, Boucek MM, et al. Fate of infants with hypoplastic left heart syndrome listed for cardiac transplantation: a multicenter study. J Heart Lung Transplant. 2005;24:576-82.

\section{Discussion}

Dr Thomas Yeh (New Orleans, La). I would like to thank Dr Guleserian for sending me the report last week and the Association for the privilege of commenting on it.

I enjoyed reading it and commend you on your efforts to learn from this, what is clearly a challenging group of patients, judging by the amount of time we all continue to spend on it. A few questions.

Because you have attempted to characterize the course of recovery with rescue banding, did you consider including a control group of conventional Norwood procedures for comparison?

Dr Guleserian. We did look back at our conventional Norwood mortality during the same time period. Of the 80 conventional Norwood procedures performed, overall mortality was $13.6 \%$ including those with presence of an extracardiac syndromes. I do not have data in terms of the hemodynamics, the fluid balance, and so forth, for that usual Norwood group in comparison to the PA banded group to answer your specific question.

Dr Yeh. I realize this was a retrospective study, but what were your specific criteria in Dallas for using this approach and have they changed now as a result of your analysis here?

Dr Guleserian. That is a very good and key question. Any time we encountered a patient with severe ventricular dysfunction, significant AVVR, or IAS or RAS high-risk group, we considered them to be high risk and suitable candidates for bilateral PA banding. Additionally, if a patient presented with renal insufficiency, renal failure, or any other end-organ dysfunction that was not immediately reversed with inotropic support and/or ventilatory changes, we would identify those patients as candidates for banding. We tend to use ductal stenting less commonly if we think that there will be rapid hemodynamic recovery in response to banding and thus be candidates for conventional Norwood pathway. For those whom we have identified as patients who do not seem like they are on that road to hemodynamic recovery, DS is undertaken.

Dr Yeh. After PAB was performed, you had several approaches to the patients, including completion Norwood rather than the comprehensive stage 2 , which you commented on briefly. What was your algorithm for a given approach (ie, DS vs prostaglandins and, more importantly, Norwood vs CS2)? I am going to ask you the same question Chris just asked, because some would argue that having stabilized the patient with the hybrid stage $1 \ldots$

Dr Guleserian. Why rock the boat.

Dr Yeh. ... Why subject the patient to the additive risk of a Norwood rather than waiting for the comprehensive stage 2?

Dr Guleserian. As an institution, our bias has been toward conventional Norwood. We really do not perform the CS2 procedure given poor results with such high-risk patients. We find that if we can rapidly turn these patients around that conventional Norwood operation is preferred to avoid the long-term pulmonary artery problems we have seen with long-term banded patients. For the patients who do not turn around-the ones for whom primary transplantation may be the most suitable option -we would pursue DS and discontinue prostaglandin therapy.

Dr Yeh. But since your original hypothesis was not met with the equivalent mortality, perhaps that is an option to consider.

Dr Guleserian. In response to your question about whether we have changed any of our management strategy: I think for patients, for example, who are extremely tiny and premature, as was one of our patients who was only $900 \mathrm{~g}$, and a former 27 -week-old neonate, the likelihood is that they are probably not going to do well. For these very high-risk patients who are extremely premature, have low birth weight, and have a small ascending aortas, we will likely still try to support these patients but avoid DS with the potential for coronary ischemia. I think that this group is best termed the worst of the worst.

Dr Yeh. Finally, in your data, unfortunately, children weighing less than $2.5 \mathrm{~kg}$ did not benefit from this approach, because the mortality was $100 \%$, a consistent risk factor that Drs Bacha and Barron actually highlighted for us over the weekend. Have you looked into the clinical behavior of that group in the perioperative period to see whether they differ fundamentally from the patients weighing more than $2.5 \mathrm{~kg}$ ? Do they behave differently? Is there something special about that group that you are noticing?

Dr Guleserian. I think the special or unique part of that particular group is that they have other significant risk factors. It is not just the weight. They were also the ones with a gestational age that are in the low 30s. In this specific group, 2 of the 4 neonates were the ones with diminutive ascending aorta and I think that our approach with DS was wrong and we should have just left them on prostaglandins. I do not know if the outcome would be different. But that is something that we have learned to avoid for the tiniest patients with a diminutive ascending aorta.

Dr Yeh. Thanks. I enjoyed reading the report.

Dr Christopher A. Caldarone (Toronto, Ontario, Canada). Kristine, 3 patients died, I believe, during the procedure. Two of 
them were pretty small. Had you deployed the DS at that point or were those patients continued with prostaglandins?

Dr Guleserian. Actually, 2 of the 3 had DSs placed. All 3 patients made it out of the operating room but they did not spend a lot of time alive out of the operating room. There were 2 patients who had DSs deployed at the time of banding, and I think that was probably an error given their diminutive ascending aortas. The third patient was a former 33-week-old, 1.8-kg patient who had received multiple doses of surfactant after delivery and got into a respiratory acidosis cycle that we could not get him out of.

Dr Caldarone. Well, I would just make 2 comments about that. In our experience, bPAB is associated with an acute bump in afterload for these hearts, and we found that they need a fair amount of inotropic support. Also, providing that up front rather than waiting for it to become apparent has been helpful. Also I think that is even more apparent in the smaller neonates.

The other issue is this issue of reverse Blalock-Taussig shunts. If these patients have events shortly after deploying of the DS, one must be worried that they had acute retrograde arch malperfusion. If that is the case, you have a choice. You can either treat it or you can try to prevent it. So, in Toronto, we use a preventive approach, which might have its own set of problems, but creates an alternative source of perfusion to the aortic arch and renders the isthmus area redundant. The alternative is to use a treatment approach. But, as you have found, it is very hard to treat these patients after they have developed acute compromise of retrograde arch perfusion.

Dr Guleserian. I would agree. And I think we are quite aggressive about afterload reduction. It is not unusual for us to give a dose of phentolamine and then initiate high-dose milrinone therapy pretty quickly. Many of these patients are coming to the operating room on pretty high-dose "rocket fuel" so to speak, so they are a very tenous group. I think all of the efforts that your group, and efforts from the experience that we just heard about in the previous presentation, will help some of these very high-risk patients make it when they might not otherwise. 